Article

\title{
Social License in the Deployment of Advanced Nuclear Technology
}

\author{
J. R. Lovering (D), S. H. Baker and T. R. Allen *(D)
}

Nuclear Engineering \& Radiological Sciences, University of Michigan, Ann Arbor, MI 48109, USA; lovering@umich.edu (J.R.L.); suzyhb@umich.edu (S.H.B.)

* Correspondence: traumich@umich.edu

Citation: Lovering, J.R.; Baker, S.H.; Allen, T.R. Social License in the Deployment of Advanced Nuclear Technology. Energies 2021, 14, 4304. https://doi.org/10.3390/en14144304

Academic Editor:

Guglielmo Lomonaco

Received: 19 May 2021

Accepted: 14 July 2021

Published: 16 July 2021

Publisher's Note: MDPI stays neutral with regard to jurisdictional claims in published maps and institutional affiliations.

Copyright: (c) 2021 by the authors. Licensee MDPI, Basel, Switzerland. This article is an open access article distributed under the terms and conditions of the Creative Commons Attribution (CC BY) license (https:/ / creativecommons.org/licenses/by/ $4.0 /)$.
Abstract: The deployment of advanced nuclear technologies is anticipated to be part of the actions required to mitigate global climate change. The successful deployment of these new technologies, like all new infrastructure projects, will be more successful if the projects have strong public support. Successful deployment of energy infrastructure correlates with thoughtful approaches to equitable energy transitions. This work recalls the history of recent energy infrastructure deployments, shows where the inclusion of social scientists has improved the possibility of success and proposes specific steps to make future deployments of advanced nuclear technologies successful.

Keywords: advanced nuclear; technology demonstration; siting; environmental justice

\section{Introduction}

The Intergovernmental Panel on Climate Change (IPCC) states that the global energy system needs to reach net-zero emissions by 2050 to avoid the worst impacts of climate change [1]. While traditional approaches may have focused on energy conservation, efficiency, and reducing the footprint of the energy system, there is a growing awareness among scientists and policy-makers that deep decarbonization will require a substantial scale-up of infrastructure. Not only will the world need to replace or retrofit existing fossil fuel energy infrastructure, but total energy consumption will grow significantly. Even without explicit climate policy, demand for electricity will at least double by 2050, simply based on projected economic growth. Of this growth in electricity demand, $90 \%$ will come from outside high-income countries [2]. With a focus on deep decarbonization, electricity demand will likely triple or quadruple by 2050, due to an increased need for electrification of transportation, industry, and residential heating.

Some have argued that such a massive build-out of clean energy infrastructure presents significant opportunities, including high-paying jobs and new industries to revitalize economically depressed regions. However, there are also significant challenges, particularly with regard to siting new energy infrastructures. For example, in the National Renewable Energy Laboratory's (NREL) 2012 Renewable Electricity Futures Study they found that the U.S. transmission network would need to double in size to handle their $90 \%$ renewable energy scenario [3]. More recently, the Net-Zero America study from Princeton University modeled five different scenarios for the U.S. achieving net-zero carbon emissions economy-wide by 2050 [4]. In their high electrification scenario, U.S. transmission infrastructure needs to increase 3.2-3.5 times by 2050; in the high electrification and high renewables scenario, transmission needs to increase by 5.3 times. Across their scenarios, the Net Zero America study found that wind farms would take up 93,000 to 400,000 square miles of land. In their constrained renewables scenario, they projected that up to 250 new $1 \mathrm{GW}$ nuclear power plants would need to be built, or 3800 Small Modular Reactors. Even though nuclear takes up significantly less land, that is still a significant siting challenge.

While technocratic models like these can tell us how much energy infrastructure needs to be built and even where, they come up short on how to actually get things built in the 
real world. This is where there is a growing need for expertise from other disciplines like public policy, sociology, science, and technology studies. Historically, policy to reduce greenhouse gas emissions (or any other air pollutant) has relied primarily on simplistic economic solutions like a carbon tax or cap and trade system. While such programs are very efficient, they tend to produce only incremental improvements at the margins, not the type of fast and deep reductions that are needed today for global greenhouse gas emissions. Countries that have been successful at large buildouts of energy infrastructure, such as France or Japan, have relied on centralized industrial policy, where top-down organizations issue mandates or targets to largely state-controlled utilities or industries. While this has been very effective-for example, in getting a lot of nuclear power built quickly - it would be difficult to reproduce in a country like the U.S. that has deregulated power markets with a large number and diversity of utilities.

For these reasons, there has been a growing consensus among climate advocates and policy-makers to shift towards a climate policy framework referred to as Standards, Investment, and Justice (SIJ). [5] Standards refers to setting performance-based standards for technologies or industries; they could be sector-specific or economy-wide like a federal Clean Energy Standard for the power sector. Investment may be self-explanatory, but recent calls are specifically for investments in the trillions of dollars for green infrastructures like transmission lines and electric vehicle charging stations. Justice is arguably the most novel in the new SIJ framework because, historically, groups like unions, fossil-dependent communities, and frontline communities have been left behind or ignored in major climate (and environmental) legislation. New climate policies focused on justice will engage with these communities from the start and will rely on them to help develop more sustainable policy options that spread the benefits and costs more equitably. Nuclear has a poor record when it comes to justice-from atmospheric weapons testing to mining on native landsand will need to develop new business and engagement models to develop new nuclear projects.

For advanced nuclear projects in the US, there is urgency in developing new siting processes. Beyond the targets for steep reductions in greenhouse gas emissions set by the Biden Administration [6], several advanced reactor designs are working through the Nuclear Regulatory Commission and could break ground on demonstration projects in the next five years [7]. Reactor developers will need to start identifying potential sites for their first commercial projects on similar timelines.

Siting will be one of the largest challenges to any accelerated clean energy transition. This paper will investigate ways to improve the process for siting by looking at case studies of both successes and failures in energy infrastructure siting. No country has built a commercial advanced nuclear project, and the US has not cited a new nuclear power plant in over 30 years. Therefore, these case studies will draw on examples from the nuclear fuel cycle as well as other large-scale energy projects. While this study focuses on mitigating siting challenges for advanced nuclear projects specifically, the lessons learned should have broader applicability to clean energy infrastructure. Importantly, as opposition to renewables and transmission has grown in recent decades, there is a need to develop just and equitable processes for siting and deployment across the energy sector. Here, there might be some lessons that nuclear can share, from its own failures and more recent successes. This study will conclude with recommendations for how to incorporate social sciences into engineering standards for clean energy deployment.

\section{Successes and Failures in Energy System Deployment}

Siting traditional nuclear power plants has a long and storied history in the US. Starting in the 1960s and continuing into the early 1970s, the Atomic Energy Commission served a dual purpose as both promoter and regulator of nuclear energy, which introduced a conflict of interest when siting projects. At this point, the moniker for the siting process for nuclear plants during this era came to be known as "decide-and-announce". Things were destined to change when in 1970 the National Environmental Policy Act (NEPA) was passed 
into law and in 1974, and the AEC was divided up, with its regulatory function given to the new, independent Nuclear Regulatory Commission. NEPA required federal agencies to perform environmental assessments for potential projects and had the potential to make the nuclear plant siting process more democratic and transparent. Instead, project developers mostly adapted to a "decide-announce-defend" model, with significant resources now going to fight lawsuits from local groups who were now using NEPA to stop projects [8]. Due to a confluence of events, including mounting opposition following Three-Mile Island, cost escalation, and stagnant demand for electricity, no new nuclear power plants have been sited in the U.S. in more than three decades. This provides the industry with an opportunity to start fresh with more equitable processes with the new suite of advanced reactor projects that will become commercially available over the next decade.

Historically, public opinion of nuclear energy has been driven by concerns over energy security and major accidents [9]. Gupta et al. (2019) found that support for nuclear energy was at a low point, averaging $49 \%$ over the last few years. Yet research from the same group found that support for new nuclear technologies, specifically Small Modular Reactors, was higher than for traditional large-scale nuclear, and support for new builds at existing nuclear sites was higher than for new sites [10]. Yet high public support may not mitigate local opposition to projects. For example, in the US there is consistently high public support for wind energy - often above $80 \%$-yet a similarly high proportion of wind projects face local opposition to siting [11].

Looking at opposition more broadly, Boudet (2019) surveyed studies of public perception of new and emerging energy technologies and found that opinion was shaped by four factors: technology, people, place, and process [12]. In the short term, nuclear technologies cannot be fundamentally changed, and unfortunately nuclear falls into unfavorable categories for many metrics. In the longer term, there should be more explicit efforts to innovate nuclear technologies to make them more appealing to consumers: smaller, simpler, fast to build.

People and place may also be difficult to control, although project developers can select locations that have favorable demographics, higher trust in government, existing infrastructure, or amenable social or political institutions. The last factor, process, is where there is the most room for improvement, and where technologists have often devoted insufficient resources. The process includes aspects of public engagement, transparency, economic incentives, and ideas of fairness or equitability.

It is clear that the nuclear industry needs to develop new processes for siting advanced nuclear projects that are improved upon historic siting decisions. To understand how to site nuclear power plants in a just and equitable way, we need to look outside the nuclear power sector. The case studies below will explore both failures and successes in siting large energy infrastructure projects, and how the outcome was influenced by the process and the inclusion or exclusion of social sciences.

\subsection{Yucca Mountain and U.S. Nuclear Waste}

Although the U.S. had been generating commercial nuclear waste since the 1950s, federal legislation to address waste was not passed by congress until 1982. The Nuclear Waste Policy Act directed the federal government to take ownership of all commercial high-level nuclear waste by 1998 and to begin a process of evaluating sites and selecting three for further study, with at least one in the east and one in the west. Nine sites were identified based on geologic studies performed in previous decades, then narrowed down to five sites based on preliminary Environmental Assessments. In 1986, the Department of Energy performed a Multi-attribute Utility Analysis on the five sites. This analysis mostly included technical, geologic, and environmental metrics, although it did include some socio-economic metrics where the impact of the surrounding community was ranked from 1-5 for variables such as health and public safety, economic impact, impact on historical sites, and biological impacts [13]. As a result of this analysis, three sites were selected for more detailed study: Yucca Mountain, Deaf Smith County Texas, and Hanford Washington. 
Just a few months later, the Department of Energy (DOE) decided that Yucca Mountain was the superior site based mainly on geology, and a 1987 amendment to the NWPA directed the DOE to focus solely on Yucca Mountain.

While the preliminary Environmental Assessments were open to public comment, there was no public engagement process around any of these potential sites. Even the socio-economic metrics were assessed by outside experts. The initial selection of potential sites and each successive narrowing down of site was based primarily on technical metrics. In the 15 years after 1987, over USD 4 billion was spent to characterize Yucca Mountain as the nation's sole geologic repository. However, during this same time, Senator Harry Reid from Nevada was elected in 1987 and grew in power to have various leadership roles through the 1990s and 2000s, eventually becoming Senate Majority leader from 2007-2015. Reid had long opposed Yucca Mountain, citing potential environmental or security risks, and saying Nevada did not want to be the nation's nuclear waste dump.

Context matters here. It is important to note that the western half of the U.S. has very few nuclear power plants compared with the eastern half; Nevada has none. There is also a long history of atomic weapons testing in Nevada and fallout affecting communities without their knowledge. Even though communities surrounding Yucca Mountain grew to be supportive of the project, the top-down selection process without community engagement cast a shadow over the site. While the choice was ultimately made at the federal level, it was unforeseen that Senator Harry Reid would become so powerful in the decision-making process, ultimately pressuring President Obama to cut funding for the project.

In response, President Obama chartered the Blue Ribbon Commission on America's Nuclear Future in 2010 to evaluate alternatives to Yucca Mountain for high-level waste. Some of the recommendations included consent-based siting, an independent agency to manage nuclear waste, and interim storage, although none of these have been implemented to date.

\subsection{Opposition to Wind Farms}

While nuclear waste may seem like an obvious project for communities to oppose, studies have also shown opposition to wind turbines across North America [14], Europe $[15,16]$, Australia [17,18], and China [19,20]. For example, Giordono et al. (2018) found that $81 \%$ of proposed wind projects in the Western U.S. faced opposition in some form (e.g., editorial letters, public testimony, lawsuits, petitions, and rallies) [11].

In the abstract, wind energy has very high public support, which is why opposition at the local level has often been characterized as a classic case of Not in My Backyard (NIMBY). Yet more recent studies suggest that the explanation is more nuanced, noting that variables on attitudes like anticipated impacts, fairness of the siting process, and place attachment can have a larger impact than a simple cost-benefit analysis. Interestingly, studies have found that perceptions of both positive and negative impacts from proposed wind farms are influenced by underlying values. Ultimately, the fairness of the process for siting wind farms is a common cause of opposition.

Bessette \& Mills (2021) found lower opposition to wind projects in areas with more production-oriented farming and fewer natural amenities like parks [21]. Groth and Vogt (2014) took a deeper look at wind energy perceptions across four townships in a single county in Michigan. They found that social factors were more important in determining support for wind development than environmental or economic factors [22]. Mills et al. (2019) surveyed residents of Michigan before and after wind farms were built locally, and found that where the planning process was perceived as fair, residents perceived greater benefits from the project. Whereas those who perceived the planning process as unfair found greater negative impacts from the wind projects, including negative impacts on property values, noise and visual impacts, and public health problems. [23]

As final approval for wind power can often come at the local level, small opposition movements can be extremely powerful in blocking projects. Building strong local support 
is more than just ensuring economic benefits. Communities want a fair and transparent process where they can have their concerns heard and addressed.

\subsection{Keystone XL Pipeline}

In the reverse, the Keystone XL pipeline is a prime example of a Yes in My Backyard (YIMBY) infrastructure project. Originally proposed in 2005, the Keystone XL pipeline would have expanded pipeline capacity (along a shorter route) bringing crude oil from Alberta in Canada to export terminals along the gulf coast in the U.S. Unusual for a large infrastructure project, it was those living closest to the pipeline's route that were most supportive of the project, primarily because of estimates that construction was estimated to generate 2500-4650 jobs, along with local property tax revenue. The U.S. President has the authority to approve energy and telecommunications infrastructure that crosses international borders, and starting with President Johnson in 1968, this task was delegated to the State Department who was charged with determining if the project in question would serve the national interest. This meant that even though communities living along the pipeline route felt that the economic benefits outweighed the potential environmental risks, the ultimate decision was made at the national level.

At the national level, support was very low, although split along party lines. Environmental groups and Native American groups filed several lawsuits to stop the project. President Obama and President Biden both rejected the permit on grounds that the negative consequences of the pipeline-increased greenhouse gas emissions, potential for oil leaks-outweighed the very small benefits, as most of the oil was headed for export terminals, not U.S. consumption. President Trump did approve the pipeline in 2020 on broad grounds of energy independence, but President Biden reversed the approval on his first day in office. What this case highlights is that, while it is very important to have local support for infrastructure projects, developers should be attuned to the points of decision-making and understand where the largest risks occur.

This parallels something that is also observed with first-of-a-kind nuclear projects, especially in newcomer countries [24]. Projects may be pushed forward with significant government support, but get abandoned when the administration changes. Building a diverse network of stakeholders who support the project at different levels can mitigate the risk that a project's success is left up to political whims.

\subsection{Nuclear Waste in Sweden and Finland}

While siting of a geologic repository for nuclear waste in the U.S. is a prime example of a siting failure, Sweden and Finland are often held up as examples of a fair and successful siting process for nuclear waste, although the details show it is more complex.

In Sweden, progress on nuclear waste disposal had a similarly slow start as in the U.S. An act of parliament in 1977 prohibited fuel loading at new nuclear reactors unless the plant owner had a plan for how and where they would safely store spent fuel. In 1980, a national referendum passed that would phase out nuclear power by 2010. In 1985, a new law was passed that loosened the rules on nuclear waste to simply require ongoing research by utilities into radioactive waste disposal [25]. However, with a clear mandate to phase out nuclear power, and a decision against reprocessing in 1985, utilities knew exactly how much nuclear waste they would need to store and began looking for sites. Unlike in the U.S., nuclear waste in Sweden is managed by a subsidiary of the private and publicly owned utilities, called the Swedish Nuclear Fuel and Waste Management Company (SKB).

The SKB began a technocratic process in the 1980s to find the absolute best bedrock for nuclear waste disposal, and they identified ten potential sites across Sweden where they planned to begin test drilling. However, local citizen groups quickly formed in opposition to these test drillings as they felt that nuclear waste was being forced upon them [25]. SKB changed its strategy and in 1992 announced a new plan that focused on volunteerism, dialogue, and just good enough geologic conditions. They started by sending an open letter to all 286 Swedish municipalities explaining the need for a nuclear waste repository and 
telling communities to reach out if they were interested in a feasibility study. Importantly, SKB stressed in the letter that any feasibility study would not lock the community into a future repository and they would always have veto authority.

Several communities showed interest and SKB focused on two communities in northern Sweden, mainly because it was sparsely populated. However, the feasibility studies were completed by outside technically-focused groups, and the communities felt excluded. Local opposition movements grew and some passed referendum to reject a future repository. One contributing factor might have been that these northern communities had no experience with nuclear facilities, as all of Sweden's nuclear power plants are located in the south. In 1994, SKB decided to shift tactics again and instead focus on volunteer communities that already hosted nuclear facilities and include more social and non-technical evaluations in the feasibility studies. They also decided to put control of the feasibility studies in local hands. Oskarshamn asked the government for additional funding to develop local expertise in nuclear waste issues [26]. Additionally, SKB signed an agreement with both communities to compensate them up to USD 245 million for the studies, with most of the funds going to the community that was not chosen for the geologic repository. The assumption being that the winning community would receive significant economic benefits through employment. SKB chose Östhammar due to its superior geology and applied for a license in 2011, and after completing more safety studies, the license was approved in 2020. Sweden does have some unique attributes that also aided in the success of their waste repository siting. Public trust in the nuclear industry and the waste management agency was significantly higher than the EU average [26].

While Finland may get lumped into a positive Scandinavian story about nuclear waste, their process was quite different than in Sweden. Significantly, Finland did not rely on volunteerism for community selection; they began with a site identification process in the 1980s based purely on geology but discovered that the bedrock was largely similar across Finland. They chose two communities based on geology, but mostly because they had existing nuclear power plants. This was not as alarming as it had been in the early Swedish process because Finnish communities always had an absolute veto right on potential projects. Nuclear waste in Finland was managed by a private entity, Posiva, which is owned by Finland's two nuclear power plant companies. Once these two communities were selected, Posiva wanted to design a fair process that opened a dialogue with communities, but their initial studies found that most people were fairly disinterested or apathetic about a hypothetical repository. To encourage more community engagement, Posiva put municipalities in charge of the federally required Environmental Impact Assessment (EIA) process. In each community, they organized groups that combined outside issue experts with local leaders who guided the process. Posiva also developed a public outreach campaign that included public meetings, exhibitions, and public opinion surveys. Based on these activities, they then organized a series of structured seminars to address concerns that were raised and included them in the EIA. Notably, many of the concerns were not technical: a large concern early on was how the repository would affect the image of the community. Posiva explored the images of several communities and found that Loviisa was already largely associated with nuclear power, another was associated with past pollution problems, a third was thought of as a natural wilderness, and the fourth, Eurajoki, was relatively unknown outside its borders. Posiva also investigates concerns about the impact on agricultural reputation.

Around this time, both communities saw a growing number of letters to the editor in the local paper expressing support for hosting the repository, mainly based on perceived economic benefits. Another common theme in such letters was that these communities had a moral obligation to host a waste repository because they had long benefited from hosting nuclear power facilities. This reflects the opposition in northern Sweden to a repository because they did not have any nuclear facilities. Posiva also designed the approval process to be staged, with many points when communities were given the opportunity to opt out. They also wanted to focus on exploring all alternatives, but the communities quickly 
realized the alternatives were limited: either approve a geologic repository or leave the waste sitting in temporary storage on-site.

In the end, there was a small majority opposed to a repository in Loviisa, but a significant majority in favor at Eurajoki, so that is where Posiva decided to site the repository. This also made sense because a large share of spent fuel was already located in Eurajoki.

In 2001, the Finnish parliament voted 159-3 to approve the geologic repository at Eurojoki, even garnering the support of the Green Party. In retrospect, it may seem that Eurajoki was always the preferred site, but the focus on developing a staged process with community veto rights was very important, as can be seen in the high community approval of the project. Also important, surveys found that trust in nuclear waste solutions was higher in communities with nuclear power plants than elsewhere in Finland.

\subsection{Synthesis across Case Studies}

While these case studies offer very different examples of siting energy infrastructure, important lessons can be drawn from each. At first glance, it looks like the US and Finnish nuclear waste siting process had some similarities, in that very few sites were considered and ultimately one site was preferred from the beginning. The big difference was in the process and the distribution of harms and benefits.

Most importantly, community engagement needs to be built in from the beginning, not something to worry about after the siting decision has been made. Going further, the most successful projects found ways to involve local leaders in the decision-making process, e.g., involving them in Environmental Impact Statements. Even when communities are engaged, the process can fail when project developers do not acknowledge imbalances in power or expertise. A community may not have the financial resources and technical expertise to meaningfully engage in a siting decision, and they may be distrustful of outside experts that are provided by project developers or government agencies. Creative funding mechanisms for communities can empower them to develop expertise and make a significant contribution to the process. Most importantly, communities that feel they had control over the process are more supportive of the outcome.

Completing large-scale energy projects can often take several years, if not decades. There is plenty of time for opposition to grow and mature in its tactics. Therefore, earning local support early in the process is key, especially when the ultimate decision on a project will be made at a higher level.

\section{Progress in Nuclear Siting}

While no commercial advanced reactor projects have been constructed in the US, there are two recent examples of new ways of siting and developing projects that are worth learning from as well.

\subsection{The NuScale Story}

The Utah Municipal Power Systems (UAMPS) is a state authorized nonprofit that provides electricity, power, transmission, and other energy related services across Utah, Idaho, Nevada, New Mexico, Wyoming, and California. A unique business model, its 47 municipal members opt in or out of different projects to meet their various energy needs [27]. According to their website, "UAMPS provides comprehensive energy services to its members, including planning, financing, developing, acquiring, constructing, operating and maintaining varied projects and transmission for the benefit of members." Historically, projects include hydro-electric, coal, natural gas, wind, waste heat to power, and all aspects of the transmission regional transmission system.

In 2015 UAMPS partnered with NuScale, a small modular reactor (SMR) company, to launch the Carbon Free Power Project (CFPP) — the first nuclear project for UMAPS and potentially the first commercial SMR to be built in the US. UAMPS members concerned about climate change wanted to start the process of decarbonizing their energy system. Due to their unique business model, member concerns carry significant weight and project risks 
are shared across many stakeholders, making UAMPS a well-suited candidate for early adoption of SMR technology. Another favorable aspect of the project is the proximity to the US Department of Energy's Idaho National Laboratory, which sits right in the center of its member area and offers many decades of experience with nuclear energy technologies.

As another layer of risk reduction for the project, a site at the Idaho National Laboratory was chosen to host the NuScale SMR as a part of a public-private partnership model between the Department of Energy and UAMPS. This arrangement has given the project access to serious technical and financial muscle including unique research capabilities, knowledgeable staff, and importantly, several rounds of federal funding to keep the project steady. On the UAMPS side, they were able to secure significant commitments from members to uphold their end of the arrangement and move the project forward. Members have built-in off ramps, so if the project planning or costs change, they can back out without penalty. This is where their business model holds key insights to what community-based nuclear could look like going forward.

For existing nuclear energy technologies, specifically light-water reactors over $1000 \mathrm{MW}$, only the largest, regulated utilities could finance and manage such a project. For small co-ops and municipalities, the scale of large light-water reactor technology has proved unattainable in recent decades. Advanced and small modular reactors may prove a catalyst for opening up new customer bases, like UAMPS, especially as the pressures of climate change start to influence federal, state, and local energy policies and decarbonization goals. With new business models that resemble those of renewables and other smaller scale projects, advanced nuclear technologies could be a good fit for community ownership, public power authorities, municipal governments, universities, hospitals, military bases, and more. UMAPS serves as an important harbinger of a changing customer base and way of doing business.

\subsection{Energy Communities Alliance}

The Energy Communities Alliance is a Washington, DC based nonprofit organization that represents the interests of communities that host federal energy research and production facilities, such as National Laboratories. Through their New Nuclear Initiative, they are coordinating, educating, and helping communities prepare to become early adopters of advanced nuclear technologies [28]. These are communities, including and similar to the Idaho National Laboratory mentioned above, who have deep histories of working at the forefront of nuclear technology, and want to continue that legacy. This represents a shift from top-down to bottom-up efforts to site a nuclear power plant.

\section{Conclusion and Policy Recommendations}

The case studies illustrate that the process in which communities participate in energy siting decisions correlates well with successful or unsuccessful deployment. Given that developers of advanced nuclear concepts envision many different sizes and types of nuclear energy systems, with many more deployment scenarios than those used for the first generation of commercial nuclear energy plants, the industry needs to develop best practices for community engagement to optimize the chance of success.

For nuclear energy system deployment, the Nuclear Regulatory Commission does have a participatory process to engage the public in regulatory decisions about the safety of a proposed reactor. They start when a developer has identified a desired technology and location but do not broadly look beyond the public safety aspects of these deployments. For the successful long-term acceptance of a project, the community needs to be engaged well before the Nuclear Regulatory Comissions (NRC) process is initiated. The deployment process needs to be consent-focused rather than just developer-focused.

The 2012 Report to the Secretary of Energy from the Blue Ribbon Commission on America's Nuclear Future noted the key challenges in siting waste facilities [29], stating "finding sites where all affected units of government, including the host state or tribe, regional and local authorities, and the host community, are willing to support or at least 
accept a facility has proved exceptionally difficult." As seen in the case studies from Section 3, these same challenges are likely for siting new nuclear energy facilities. The Blue Ribbon Commission noted, "The approach we recommend also recognizes that successful siting decisions are most likely to result from a complex and perhaps extended set of negotiations between the implementing organization and potentially affected state, tribal, and local governments, and other entities."

While there are indications that nuclear waste siting processes are more successful when pursued in a consent-base process, there are wide knowledge gaps in understanding best practices for consent-base siting. What then might the elements of a consent-base program include? How might the elements of a consent-base process be structured? How might the elements of governmental programs be restructured to better support transitioning to a consent-base process?

In terms of a Standards, Investment, and Justice (SIJ) framework, nuclear developers typically use well defined and understood guidelines for proving the technology, meeting regulatory requirements, and making finance determinations. Engineering communities often use standards, operational guidelines, and regulatory guidelines as a method of ensuring consistency and best practices in the construction and operation of complex engineering systems. These standards, operational guidelines, and regulatory guidelines typically outline indicators of successful performance and ways to measure that performance. They ask questions such as:

- What are the credible damage mechanisms for each plant application?

- What types of failures of a component affect functionality and which do not?

- What is the operating history from the current equipment installations?

There are no similar guidelines for the best practices in siting and community engagement, but parallel questions might be framed such as:

- How might a specific nuclear plant design lose community support?

- Which community responses could cause the plant to be shut down and which would not?

- What is the history of similar nuclear plants in different social contexts?

While a set of prescriptive guidelines is not likely useful for consent-base siting, Webler and Tuler [30], drawing from the consent literature for medical treatment, human subjects, political theory, and land use planning found common elements that should be delineated in the specific context of an energy system deployment.

- Consent givers must be self-directed and able to give consent. This consent must be voluntary and not coerced. "Consent-based approaches give a community authority to reject an offer outright, based on their own understandings of risk and benefits, but key to the successful remediation of competing private and public interests is a requirement that an offer is given due consideration." Consent givers must ultimately determine if the project risk is worth the benefits.

- Consent seekers "must agree to negotiating about a wider array of issues related to community well-being and not limit the negotiations to the proposed facility".

- Expressing consent. Guidelines must be set as to determining how and when consent is expressed. This will be different in each deployment scenario as the intersections of local decision-making bodies, marginalized groups, and affected surrounding communities will have unique cultures and histories. "For example, if the procedural rules are imposed by "outsiders," then local acceptance may suffer because people see the imposition as undermining local autonomy. At the same time, putting the power to define a process in the hands of local authorities can challenge the autonomy of politically marginalized groups or abutting communities."

A consent-base process could also be informed by the method used by standards bodies such as the American National Standards Institute (ANSI) [31]. The ten essential requirements for establishing a standard established by ANSI are highlighted in Figure 1 [31]. Essentially, these requirements collectively require: transparency of the process, inclusivity 
such that all interested parties can participate and no one interest is allowed to dominate, consensus decision-making, public review of decisions, and an ability to appeal decisions. These processes are similar to those established by the 2003 National Academies "One Step at a Time" report on adaptive staging that recommended the following steps [32]:

- Commitment to systematic learning. Project managers intentionally seek, are open to, and learn from new knowledge and stakeholder input. Stages are designed specifically to increase available scientific, technical, societal, institutional, and operational knowledge.

- Flexibility. Project managers are able and willing to reevaluate earlier decisions and redesign or change course when new information warrants.

- Reversibility. Project managers are able to abandon an earlier path and reverse the course of action to a previous stage if new information warrants.

- Transparency. The decision-making process and the basis

- $\quad$ For decisions are documented and accessible in real-time and plain language to all stakeholders.

- Auditability. Documentation for the basis of decisions is complete and made available to all interested parties for review purposes.

- Integrity. Technical results are accurately and objectively reported and all uncertainties, assumptions, and indeterminacies are identified and labeled.

- Responsiveness. Project managers seek and act on new information in a timely fashion.

Finally, changes to the execution of governmental programs could incentivize better consent-base approaches and the development of trained practitioners in the best practices of consent-base siting. Recommendations include [33]:

- The Department of Energy's Office of Nuclear Energy should create and fund a social science agenda with the goal of achieving more equitable adoption of advanced reactor technologies. Such a program should focus on addressing historic inequalities in nuclear technology access, expediting legacy clean-up efforts, ensuring community participation in the development of advanced nuclear projects, and fulfilling the federal government's responsibility on nuclear waste.

- Nuclear energy should be recognized as a tool of climate diplomacy, including funding for nuclear through international development and foreign aid packages. The Department of Energy should prepare for the export of advanced reactors while recognizing the diverse energy needs of emerging economies. DOE and State Department should work together to develop meaningful Research Development and Demomstrations (RD\&D) partnerships with emerging nuclear countries that advance the best in technology, economics, public policy, and social science with allied countries.

- Domestically, DOE should fund community-led climate planning and feasibility studies to enable communities to self-assess and self-determine if advanced nuclear technologies are right for them.

- $\quad$ For demonstration and deployment of new nuclear technologies, DOE should adopt a sociotechnical approach that integrates consideration of technology, geography, economics, politics, social issues, and historical context. 
1.0 Essential requirements for due process

Due process means that any person (organization, company, government agency, individual, etc.) with a direct and material interest has a right to participate by: a) expressing a position and its basis, b) having that position considered, and c) having the right to appeal. Due process allows for equity and fair play. The following constitute the minimum acceptable due process requirements for the development of consensus.

1.1 Openness

Participation shall be open to all persons who are directly and materially affected by the activity in question. There shall be no undue financial barriers to participation. Voting membership on the consensus body shall not be conditional upon membership in any organization, nor unreasonably restricted on the basis of technical qualifications or other such requirements.

1.2 Lack of dominance

The standards development process shall not be dominated by any single interest category, individual or organization. Dominance means a position or exercise of dominant authority, leadership, or influence by reason of superior leverage, strength, or representation to the exclusion of fair and equitable consideration of other viewpoints.

1.3 Balance

The standards development process should have a balance of interests. Participants from diverse interest categories shall be sought with the objective of achieving balance. If a consensus body lacks balance in accordance with the historical criteria for balance, and no specific alternative formulation of balance was approved by the ANSI Executive Standards Council, outreach to achieve balance shall be undertaken.

1.4 Coordination and harmonization

Good faith efforts shall be made to resolve potential conflicts between and among existing American National Standards and candidate American National Standards.

1.5 Notification of standards development

Notification of standards activity shall be announced in suitable media as appropriate to demonstrate an opportunity for participation by all directly and materially affected persons.

1.6 Consideration of views and objections

Prompt consideration shall be given to the written views and objections of all participants, including those commenting on the PINS announcement or public comment listing in Standards Action.

1.7 Consensus vote

Evidence of consensus in accordance with these requirements and the accredited procedures of the standards developer shall be documented.

\subsection{Appeals}

Written procedures of an ANSI-Accredited Standards Developer (ASD) shall contain an identifiable, realistic, and readily available appeals mechanism for the impartial handling of procedural appeals regarding any action or inaction. Procedural appeals include whether a technical issue was afforded due process.

1.9 Written procedures

Written procedures shall govern the methods used for standards development and shall be available to any interested person.

1.10 Compliance with normative American National Standards policies and administrative procedures

All ANSI-Accredited Standards Developers (ASDs) are required to comply with the normative policies and administrative procedures established by the ANSI Executive Standards Council or its designee.

Figure 1. Essentials of a standard, from the American National Standards Institute.

Author Contributions: Conceptualization, T.R.A.; methodology, J.R.L., S.H.B., and T.R.A.; investigation, J.R.L., S.H.B., and T.R.A.; writing-original draft preparation, J.R.L., S.H.B., and T.R.A.; writing-review and editing, J.R.L., and T.R.A.; funding acquisition, S.H.B., and T.R.A. All authors have read and agreed to the published version of the manuscript.

Funding: This research received no external funding.

Institutional Review Board Statement: Not applicable.

Informed Consent Statement: Not applicable.

Data Availability Statement: Not applicable.

Conflicts of Interest: The authors declare no conflict of interest. 


\section{References}

1. IPCC. Summary for Policymakers. In Global Warming of 1.5 C; An IPCC Special Report on the impacts of global warming of $1.5 \mathrm{C}$ above pre-industrial levels and related global greenhouse gas emission pathways, in the context of strengthening the global response to the threat of climate change, sustainable development, and efforts to eradicate poverty; World Meteorological Organization: Geneva, Switzerland, 2018.

2. Kempfer, J.; Freed, J.; Moss, T.; Lovering, J.; Kincer, J. Mapping the Global Market for Advanced Nuclear; Third Way, Washington, DC, USA. 2020. Available online: https:/ / www.thirdway.org/memo/mapping-the-global-market-for-advanced-nuclear (accessed on 15 July 2021).

3. NREL. Renewable Electricity Futures Study; NREL: Golden, CO, USA, 2012; Volume 1.

4. Larson, E.; Greig, C.; Jenkins, J.; Mayfield, E.; Pascale, A.; Zhang, C.; Drossman, J.; Williams, R.; Pacala, S.; Socolow, R. Net-Zero America: Potential Pathways, Infrastructure, and Impacts; Interim Report; Princeton University: Princeton, NJ, USA, 2020.

5. Roberts, D. At Last, a Climate Policy Platform That Can Unite the Left. Vox, 9 July 2020. Available online: https:/ /www.vox.com/ energy-and-environment/21252892/climate-change-democrats-joe-biden-renewable-energy-unions-environmental-justice (accessed on 15 July 2021).

6. White House Press Release. FACT SHEET: President Biden Sets 2030 Greenhouse Gas Pollution Reduction Target Aimed at Creating Good-Paying Union Jobs and Securing U.S. Leadership on Clean Energy Technologies. 2021. Available online: https://www.whitehouse.gov/briefing-room/statements-releases/2021/04/22/fact-sheet-president-biden-sets-2030 -greenhouse-gas-pollution-reduction-target-aimed-at-creating-good-paying-union-jobs-and-securing-u-s-leadership-onclean-energy-technologies / (accessed on 15 July 2021).

7. U.S. Nuclear Regulatory Commission. Advanced Reactors: Pre-Application Activities. Available online: https://www.nrc.gov/ reactors/new-reactors/advanced/details.html\#preAppAct (accessed on 15 July 2021).

8. Ebbin, S.; Kasper, R. Citizen Groups and the Nuclear Power Controversy; The MIT Press: Cambridge, MA, USA, 1974.

9. Gupta, K.; Nowlin, M.C.; Ripberger, J.T.; Jenkins-Smith, H.C.; Silva, C.L. Tracking the nuclear 'mood' in the United States: Introducing a long-term measure of public opinion about nuclear energy using aggregate survey data. Energy Policy 2019, 133, 110888. [CrossRef]

10. Jenkins-Smith, H.C.; Silva, C.L.; Ripberger, J. American Views of Nuclear Energy Technologies: Summary Report on Public Support for Small Modular Reactors; University of Oklahoma: Norman, OK, USA, 2018.

11. Giordono, L.S.; Boudet, H.S.; Karmazina, A.; Taylor, C.L.; Steel, B.S. Opposition “overblown”? Community response to wind energy siting in the Western United States. Energy Res. Soc. Sci. 2018, 43, 119-131. [CrossRef]

12. Boudet, H.S. Public perceptions of and responses to new energy technologies. Nat. Energy 2019, 4, 446-455. [CrossRef]

13. A Multi-Attribute Utility Analysis of Sites Nominated for Characterization For the First Radioactive-Waste Repository? - A decision Aiding Methodology; U.S. Department of Energy: Washington, DC, USA, 1986; pp. 5-16.

14. Rand, J.; Hoen, B. Thirty years of North American wind energy acceptance research: What have we learned? Energy Res. Soc. Sci. 2017, 29, 135-148. [CrossRef]

15. Jones, C.R.; Richard Eiser, J. Understanding 'local' opposition to wind development in the UK: How big is a backyard? Energy Policy 2010, 38, 3106-3117. [CrossRef]

16. Waldo, Å. Offshore wind power in Sweden-A qualitative analysis of attitudes with particular focus on opponents. Energy Policy 2012, 41, 692-702. [CrossRef]

17. Hall, N.; Ashworth, P.; Devine-Wright, P. Societal acceptance of wind farms: Analysis of four common themes across Australian case studies. Energy Policy 2013, 58, 200-208. [CrossRef]

18. Hobman, E.V.; Ashworth, P. Public support for energy sources and related technologies: The impact of simple information provision. Energy Policy 2013, 63, 862-869. [CrossRef]

19. Guo, Y.; Ru, P.; Su, J.; Anadon, L.D. Not in my backyard, but not far away from me: Local acceptance of wind power in China. Energy 2015, 82, 722-733. [CrossRef]

20. Yuan, X.; Zuo, J.; Huisingh, D. Social acceptance of wind power: A case study of Shandong Province, China. J. Clean. Prod. 2015, 92, 168-178. [CrossRef]

21. Bessette, D.L.; Mills, S.B. Farmers vs. lakers: Agriculture, amenity, and community in predicting opposition to United States wind energy development. Energy Res. Soc. Sci. 2021, 72, 101873. [CrossRef]

22. Groth, T.M.; Vogt, C.A. Rural wind farm development: Social, environmental and economic features important to local residents. Renew. Energy 2014, 63, 1-8. [CrossRef]

23. Mills, S.B.; Bessette, D.; Smith, H. Exploring landowners' post-construction changes in perceptions of wind energy in Michigan Land Use Policy 2019, 82, 754-762. [CrossRef]

24. de Kirby, K.; Lovering, J. A Socially Sustainable Future for Nuclear Energy in Emerging Markets; The Breakthrough Institute: Oakland, CA, USA, 2021.

25. Elam, M.; Sundqvist, G. Stakeholder involvement in Swedish nuclear waste management. 2006, 73. Available online: https: / / www.researchgate.net/publication/255558104_Stakeholder_Involvement_in_Swedish_Nuclear_Waste_Management (accessed on 15 July 2021).

26. Lidskog, R.; Sundqvist, G. On the right track? Technology, geology and society in Swedish nuclear waste management. J. Risk Res. 2004, 7, 251-268. [CrossRef] 
27. UAMPS. Projects. Available online: https://www.uamps.com/Projects (accessed on 5 February 2021).

28. Energy Communities Alliance. New Nuclear Initiative. Available online: http:/ / www.energyca.org/new-nuclear (accessed on 5 February 2021).

29. Blue Ribbon Commission on America's Nuclear Future. Report to the Secretary of Energy; U.S. Department of Energy: Washington, DC, USA, 2012. Available online: https:/ / www.energy.gov/sites/prod/files/2013/04/f0/brc_finalreport_jan2012.pdf (accessed on 15 July 2021).

30. Webler, T.; Tuler, S. Unpacking the idea of democratic community consent-based siting for energy infrastructure. J. Risk Res. 2021, 24, 94-109. [CrossRef]

31. American National Standards Institute (ANSI). About ANSI. Available online: https://www.ansi.org/about/introduction (accessed on 5 February 2021).

32. National Research Council. One Step at a Time: The Staged Development of Geologic Repositories for High-Level Radioactive Waste; The National Academies Press: Washington, DC, USA, 2003. [CrossRef]

33. Our Progressive Policy Agenda for Advanced Nuclear Energy, Recommendations for Advanced Nuclear Technologies as Part of the U.S. Climate Change Response. Available online: https://www.goodenergycollective.org/policy/progressive-policyagenda-for-advanced-nuclear-energy (accessed on 15 July 2021). 